\title{
PATTERN PRACTICE-COMPLETELY ORAL
}

\author{
ROBERT LADO \\ University of Michigan
}

$\mathrm{E}$ VEN WHEN a foreign language student has fully grasped the im-
port of a pattern and can produce it by consciously selecting and putting together its elements, if the pattern does not exist in his native language, he will probably distort it when attempting to use it in a normal speech situation. As long as he devotes his full attention to producing the pattern he may do it well but haltingly, but the moment he concentrates on the subject of the conversation his production is likely to fall back on past habit, and systematic distortions of the pattern will probably occur.

This persistent tendency does not result primarily from stubborness or lack of interest on the part of the student; it is normal behavior and it results primarily from the student's native language habits and the necessity of depending on habit to speak a language effectively.

The theoretical solution to this problem is not difficult to discover, although perhaps because of its very simplicity it has long and often been overlooked or considered only lightly. Only when new automatic habits have been established that will operate when the speaker's attention is primarily on what he wants to say rather than on the mechanics of the language will the student speak the language well. Charles $\mathrm{C}$. Fries writes, "The fundamental matters of the language that must be mastered on a production level should, as soon as possible, be made unconscious habits." 1

Once the necessity to establish habits in learning a foreign language is fully realized, however, there still remains the problem of establishing those habits efficiently. Simple repetition, workbook exercises, and free conversation are often used. Simple repetition

1 Charles C. Fries, Teaching and Learning English as a Foreign Language, University of Michigan Press, Ann Arbor, 1945, p. 8. 
of the pattern, although better than no repetition, does not of itself constitute an efficient technique. Boredom soon sets in, and the will to learn weakens and eventually disappears. Workbook type exercises have little effect on the establishment of automatic habits. They depend on conscious attention to the clues that determine the form of the pattern, and as a result, when the speaker uses the language in a normal speech situation, having to devote primary attention to meaning, he reverts to his native language habits, which are largely automatic. In free conversation, probably the most desirable of the three types of exercises mentioned, each pattern appears too infrequently, and concentrated practice cannot easily be achieved. Furthermore, the instructor is constantly faced with a choice between either breaking the student's train of thought with constant corrections or allowing the unacceptable forms to go unchecked. Of course, the above techniques have value and can be employed advantageously at proper stages, but other techniques need to be developed that will prove more efficient in establishing unconscious habits in the foreign language.

Pattern practice-completely oral-is presented here as one such technique. It consists paradoxically in the conscious substitution of some element other than the chief element being taught so that primary attention is drawn away from it while the entire pattern is repeated. The instructor presents the pattern orally and the students repeat it until they can produce it easily. The instructor then provides substitutions orally while the students repeat the complete pattern including the substitution. An illustration will clarify this statement and set forth the technique itself.

A rather common error among Spanish and Portuguese speakers learning English is the addition of to after must in the pattern, "I must go to the library." They are inclined to say, "I must to go to the library." This tendency results from the student's native language habit of using que in a similar pattern (Spanish, "Tengo que ir"; Portuguese, "Eu tenho que ir."). An English pattern having to in the same position- "I have to go to the library"-reinforces the tendency. The pressure to use to after must is thus unusually great.

To avoid becoming involved in preliminaries let it be assumed that the pattern has been presented and taught satisfactorily up to 
and including the stage of production with conscious choice. ${ }^{2} \mathrm{We}$ assume, then, that the student is able to produce the pattern when his primary attention focuses on the mechanics of it, but he reverts to the unacceptable "I must to go to the library" when he has to concentrate on meaning. If matters are left at this stage, the student will recite fairly well in class but he will falter in free conversation.

A completely oral pattern practice might develop as follows: The students imitate the teacher-informant in producing "I must go to the library" until they produce it with relative ease. The imitation should include intonation, stress, and rhythm as well as individual sounds. When the students are producing the pattern satisfactorily the teacher-informant provides orally a word or phrase-bank, for example-which the students substitute for library as they produce the entire pattern including the substitution. They will say, "I must go to the bank." The teacher-informant continues supplying substitutes: "post office, drug store, grocery store, shoe store, bus station." $s$

It is not difficult to analyze the kind of exercise the student goes through in completely oral pattern practice. He has to use the pat-

2 In presenting the pattern no grammatical terminology need be used. Both patterns can be presented in contrast thus:

I have to read my lesson.

I must read my lesson.

The absence of to after must stands out clearly. It should suffice to point out the difference between the patterns by saying, "Notice there is no to after must." An exercise in which to is the signal for the use of have and its absence the signal for the use of must will provide practice in production with conscious choice. The exercise could be something like the following:

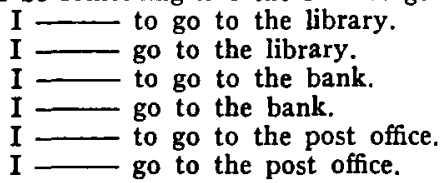

B The complete pattern with substitutions follows:

I must go to the library.

bank.

post office.

drug store.

grocery store.

shoe store.

bus station. 
tern almost automatically while concentrating on the element being supplied orally by the teacher which has nothing to do with the point being practiced. 4 He listens carefully to the teacher's production and strives to imitate it. When he succeeds, he listens acutely again for the substitution which the teacher is going to provide. When he hears it, he has to remember it long enough to produce the entire pattern including the substitution. As soon as he produces that, he has to listen again for a new substitution. The sequence of substitutions continues while the pattern itself becomes more and more automatic until finally the student can devote full attention to the substitutions. It is interesting to observe systematic errors appearing occasionally as the student shifts his attention to the substitutions. In such cases a signal from the teacher indicating that the rendition was not satisfactory will bring a second try. If the error is repeated the original pattern may have to be presented again for simple imitation.

This type of completely oral pattern practice approximates the language activity involved in free conversation while at the same time it provides the concentrated practice of simple imitation. It has been found rewarding as to sustained interest, attention, concentration, and amount of student participation. Its validity and ultimate effectiveness have not been tested experimentally, but they can be judged somewhat by observation and analysis.

4 Until the procedure is thoroughly familiar it may be easier to write the master pattern on the blackboard and to list the substitutions as in footnote 3 . This variation goes faster and proceeds more smoothly than the completely oral one and students are apt to prefer it. However the value of completely oral practice in establishing automatic habits outweighs these considerations. Writing the pattern may be used to provide needed variety of drill. 